\title{
Liberica Coffee (Coffea liberica L.) from Three Different Regions: In Vitro Antioxidant Activities
}

\author{
Muhamad Insanu ${ }^{1}$ *: (D) , Irda Fidrianny ${ }^{1}$ (D), Nur Hanin Husnul Imtinan ${ }^{1}$ (D), Siti Kusmardiyani ${ }^{1}$ (D) \\ 1 Department of Pharmaceutical Biology, School of Pharmacy, Bandung Institute of Technology, Bandung, Indonesia \\ * Correspondence: muhamad.insanu@gmail.com;
}

Received: 3.01.2021; Revised: 29.01.2021; Accepted: 2.02.2021; Published: 7.02.2021

\begin{abstract}
Free radicals are unstable molecules with unpaired electrons in their outer orbitals. An antioxidant is a compound that can be scavenged free radicals. Coffee is one of the natural antioxidants. This research aimed to study the antioxidant activity of medium roasted beans of liberica coffee (Coffea liberica) from three different regions by DPPH and CUPRAC methods. To determine total phenolic content (TPC) and total flavonoid content (TFC), analyze the correlation between TPC and TFC with AAI DPPH and CUPRAC and the correlation between two methods in sample extracts. The sample was extracted by reflux using n-hexane, ethyl acetate, and ethanol. AAI DPPH in the range of 0.397- 18.536, while CUPRAC 0.532-4.674. The highest TPC in ethanol extract of liberica coffee from Aceh $(22.585$ $\pm 1.610 \mathrm{~g} \mathrm{GAE} / 100 \mathrm{~g})$ and the highest TFC in ethyl acetate extract of liberica coffee from Aceh (4.927 $\pm 0.355 \mathrm{~g} \mathrm{QE} / 100 \mathrm{~g}$ ). TPC of all samples had a positive and significant correlation with AAI DPPH and CUPRAC. AAI DPPH and CUPRAC value gave a significant and positive correlation. TPC of liberica coffee from three different regions contributed to antioxidant activity by DPPH dan CUPRAC methods. The two methods showed linear results in antioxidant activities of liberica coffee from three regions.
\end{abstract}

Keywords: antioxidant; liberica coffee; Riau; Aceh; Jambi; DPPH; CUPRAC.

(C) 2021 by the authors. This article is an open-access article distributed under the terms and conditions of the Creative Commons Attribution (CC BY) license (https://creativecommons.org/licenses/by/4.0/).

\section{Introduction}

Free radicals are unstable molecules with unpaired electrons in their outer orbitals [1]. Our body can produce free radicals from metabolism processes, and they can also be obtained from UV-light, cigarettes, and other chemicals [2].

Antioxidants are stable molecules that can donate an electron and prevent oxidation reactions by binding to the free radicals [1]. One of the natural antioxidants that can be consumed to increase our body's antioxidant capacity can be retrieved from secondary metabolites in plants such as phenol and flavonoid compounds.

Human health can be affected by the balance of free radicals and antioxidants in the body. The accumulation of free radicals in the body can cause a decreased tissue or organ function as time goes by and cause degenerative diseases such as cancer, diabetes mellitus, hypertension, and coronary heart disease [1]. These problems are caused by the excess of free radicals that will attack the body's lipid, protein, and DNA components, which causes oxidative stress.

Coffee is one of the most famous plantation products, and this plant also can be founded in many countries. Since ancient times, coffee beans are usually processed into various kinds of food and beverages because of their unique taste. Its taste comes from some metabolites that 
the green beans had during the harvesting process or the metabolites created after a roasting process [3-5]. Drinking coffee is very usual as a lifestyle and habit for certain people [6]. Besides that, coffee beans can also be used as cosmetic ingredients, and their pharmacological effects are used to prevent degenerative diseases due to their abundant antioxidant content [78]. People in Indonesia consume Arabica(Coffea arabica), Robusta(Coffea canephora), and Liberica (Coffea liberica).

The origin of liberica coffee is Liberica, Africa. In the $19^{\text {th }}$ century, this coffee was brought to Indonesia to replace arabica coffee that pests attacked. The taste of these coffee beans is more similar to robusta coffee than arabica coffee. While arabica coffee has caramel and sweet notes, the robusta one has spicy, pungent, and earthy notes [9-10]. Meanwhile, liberica coffee beans have an aroma like jackfruits, and the size of the beans is larger than the two other types of coffee.

The coffee beans, which are generally consumed, will pass the roasting process. This process is divided into three types, light roast, medium roast, and dark roast. The roasting process will affect the taste, color, and smell of the coffee beans [11]. Medium roasted coffee is the most favorite coffee because it has a slightly sweeter taste, medium acidity and can maintain the roasted coffee beans [12].

This research aimed to study the antioxidant activity of medium roasted beans of Liberica coffee (Coffea liberica) from three different regions by DPPH and CUPRAC methods. To determine total phenolic content (TPC) and total flavonoid content (TFC), analyze the correlation between TPC and TFC with AAI DPPH and CUPRAC and the correlation between two methods in sample extracts.

\section{Materials and Methods}

\subsection{Materials.}

Medium roasted liberica coffee beans from three regions (Riau, Aceh, and Jambi), methanol, ethyl acetate, n-hexane, DPPH (2,2-diphenyl-1-picrylhydrazyl), ascorbic acid, cupric chloride, aquadest, neocuproine, ethanol, ammonium acetate, gallic acid, FolinCiocalteu reagent, sodium carbonate, quercetin, aluminum (III) chloride, and sodium acetate.

\subsection{Preparation of sample.}

Medium roasted liberica coffee beans were collected from three regions: Riau provinceMeranti Island, namely R, Aceh province-Gayo districts as A, and Jambi province-Tanjung district as J. Those samples were ground into powder.

\subsection{Extraction.}

Three hundred grams of each powdered samples were extracted using the reflux method with three different solvents' polarities (n-hexane, ethyl acetate, and ethanol). The extraction process was repeated three times for each solvent to get the maximum amount of extracts. Before changing the solvent, powdered samples were dried first. There were nine extracts: three n-hexane extracts (namely R1, A1, and J1), three ethyl acetate extracts (R2, A2, and J2), and three ethanol extracts (R3, A3, and J3). 


\subsection{Antioxidant activity index determination using DPPH method.}

Antioxidant activity determination using the DPPH method started by preparing 39.4 $\mu \mathrm{g} / \mathrm{mL}$ DPPH in methanol. Furthermore, the absorbance of DPPH was measured by UV-visible spectrophotometer Beckman Coulter DU 720 at $517 \mathrm{~nm}$ to get the $\mathrm{A}_{0}$ value. That solution can be stored in the refrigerator at $4^{\circ} \mathrm{C}$ for $24-48$ hours to reduce absorbance \pm 0.2 . Ascorbic acid as standard was prepared in a stock solution (diluted using methanol to obtain a concentration of $0.05-3 \mu \mathrm{g} / \mathrm{mL}$ ). Each ascorbic acid solution with different concentrations was pipetted into a DPPH solution (1: 1). After 30 min of incubation, the absorbance was read at $\lambda 517 \mathrm{~nm}$ using a UV-visible spectrophotometer to get a calibration curve and calculate the $\mathrm{IC}_{50}$ of ascorbic acid using the reduction of DPPH absorbance [13]. Methanol was used as a blank and 39.4 $\mu \mathrm{g} / \mathrm{mL}$ DPPH as a control. The analysis was done in triplicate for the standard and each extract. $\mathrm{IC}_{50}$ of each extract was determined using its calibration curve of DPPH absorbance. The antioxidant activity index was concluded by dividing the standard or extract concentration with IC50 value.

\subsection{Antioxidant activity index determination using the CUPRAC method.}

The antioxidant activity index was adopted from Apak et al. 2013 [14]. This method began by making $100 \mu \mathrm{g} / \mathrm{mL}$ of CUPRAC solution in ammonium acetate buffer $\mathrm{pH} 7$. This solution's absorbance was measured by UV-visible spectrophotometer Beckman Coulter DU 720 at $517 \mathrm{~nm}$ to get the $\mathrm{A}_{0}$. Ascorbic acid as standard was prepared in a stock solution (diluted using methanol to obtain a concentration of 1.5-5 $\mu \mathrm{g} / \mathrm{mL}$ ). Each ascorbic acid solution with different concentrations was pipetted into CUPRAC solution (1: 1). After 30 min of incubation, the absorbance was read using a UV-visible spectrophotometer Beckman Coulter DU 720 at $\lambda$ $450 \mathrm{~nm}$ to obtain a calibration curve and determine the $\mathrm{EC}_{50}$ ascorbic acid using the increase of CUPRAC absorbance. Ammonium acetate buffer $\mathrm{pH}$ seven was used as a blank and 100 $\mu \mathrm{g} / \mathrm{mL}$ CUPRAC as a control. The analysis was done in triplicate for the standard and each extract. $\mathrm{EC}_{50}$ of each extract was determined using its calibration curve of CUPRAC absorbance. The antioxidant activity index was concluded by dividing the standard or extract concentration with the EC50 value.

\subsection{Total phenolic content (TPC) determination.}

The total phenolic content determination was adopted from Pourmorad et al. 2006 [15] using the modified Folin-Ciocalteu method. Gallic acid as standard was prepared in different concentrations (40-130 $\mu \mathrm{g} / \mathrm{mL})$. Each gallic acid solution with different concentrations was taken $0.5 \mathrm{~mL}$ and then added with $5 \mathrm{~mL}$ of $10 \%$ Folin-Ciocalteu reagent. To the mixture $4 \mathrm{~mL}$ of sodium carbonate $1 \mathrm{M}$. After 15 min of incubation, the absorbance was measured by UVvisible spectrophotometer Beckman Coulter DU 720 at $765 \mathrm{~nm}$. Methanol with Folin-Ciocalteu and sodium carbonate was used as a blank. Each absorbance of gallic acid was applied to obtain the gallic acid calibration curve. The analysis was done in triplicate for the standard and each extract. Each extract's total phenolic content was determined using the gallic acid calibration curve and reported as a percentage of total gallic acid equivalent per $100 \mathrm{~g}$ extract ( $\mathrm{g} \mathrm{GAE} / 100$ g). 


\subsection{Total flavonoid content (TFC) determination.}

The determination of total flavonoid content was adopted from Chang et al., 2002 [16]. Quercetin as standard was prepared in different concentrations $(60-130 \mu \mathrm{g} / \mathrm{mL})$. Each quercetin solution with different concentrations was taken as much as $0.5 \mathrm{~mL}$ and then added with 1.5 $\mathrm{mL}$ of methanol, $2.8 \mathrm{~mL}$ of aqua dest, $0.1 \mathrm{~mL}$ of $10 \% \mathrm{AlCl}_{3}$, and $0.1 \mathrm{~mL}$ of sodium acetate 1 M. After 30 min of incubation, the absorbance was measured by UV-visible spectrophotometer Beckman Coulter DU 720 at $\lambda 415 \mathrm{~nm}$. Each absorbance of quercetin was used to find the quercetin calibration curve. The analysis was done in triplicate for the standard and each extract. Each extract's total flavonoid content was investigated using the quercetin calibration curve and reported as a percentage of total quercetin equivalent per $100 \mathrm{~g}$ extract ( $\mathrm{g}$ QE /100 g).

\subsection{Statistical method.}

Each sample analysis was performed in triplicate. All of the results presented in means (standard deviation). Statistical analysis using one-way ANOVA with a statistical significance level set at $\mathrm{p}<0.05$ and carried out with SPSS 20 for Window. Pearson's method was used to assign the correlation between the total phenolic, flavonoid content, antioxidant activities, and the correlation between two antioxidant activity methods.

\section{Results and Discussion}

The previous research [17-21] said that Coffea sp. had antioxidant activity. The quality and quantity of various compounds in the coffee beans depend on the coffee types, roasting process due to heterocyclic compounds formed through Maillard reactions in roasted coffee, extraction procedure, and the methodology antioxidant activity determination [6, 18, 22-26]. There are three types of roasting processes. Lightly roasted coffee is a type of coffee that is burned at $230^{\circ} \mathrm{C}$ for $12 \mathrm{~min}$. Medium roasted coffee is a type of coffee that many people favor. This type of coffee has passed the roasting process at $240^{\circ} \mathrm{C}$ for $14 \mathrm{~min}$. Simultaneously, dark roasted coffee is a type of coffee roasted at a temperature of $245^{\circ} \mathrm{C}$ for $15 \mathrm{~min}$ [11]. These roasting processes changes the chemical composition in the coffee beans, leading to the changing of flavor, aroma, and browning pigments. Roasted coffee beans contain melanoidins, which are produced from non-enzymatic browning exhibit antioxidant activity [27].

Liberica coffee beans are among the most consumed coffee globally, even though their popularity is below arabica coffee and robusta coffee [21]. There was just limited research discussing the antioxidant activity of liberica coffee. There was no study concerning the antioxidant activity of three various polarity extracts (which were n-hexane, ethyl acetate, and ethanol) from three different regions using DPPH and CUPRAC methods.

Based on the mechanism, there are two kinds of methods that can be used to determine antioxidant activity, hydrogen transfer method and electron transfer method. DPPH is an example of a hydrogen transfer method, while CUPRAC is one of the electron transfer methods. DPPH free radicals can be used to determine antioxidant activity. The color of DPPH will be changed from purple to yellow because of the reduction of DPPH by hydrogen donation. The intensity of color change is comparable with reducing DPPH absorption at wavelength 517 $\mathrm{nm}$ [13]. The antioxidant activity determination principle using the CUPRAC method is the reduction process of $\mathrm{Cu}^{2+}$ to $\mathrm{Cu}^{+}$that will form a complex with neocuproine. CUPRAC free radicals dissolve in methanol have characteristic absorption at wavelength $450 \mathrm{~nm}$ [14]. 
The results of a previous study [21] about the determination of antioxidant activity from three different types of coffee beans using the DPPH method shown that the green beans of liberica coffee have the highest antioxidant activity, followed by arabica coffee and robusta coffee. The existence of the volatile extracts in the green coffee beans may play a role in providing antioxidant activity. The main phenolic compound most linked to sugars as glycosides usually found in green coffee beans is chlorogenic and caffeic acid [27-28]. The chemical constituents include the terpene alcohols such as linalool, $\alpha$-terpineol, nerol, geraniol guaiacol, and eugenol (Z) isoeugenol, p-vinyl guaiacol, and p-vinyl phenol. Other heterocyclic components are caffeine, several furans, and pyrroles [22-31]. Liberica coffee has the highest antioxidant activity due to the higher content of non-phenolic antioxidants than other coffee types. A study by Patay EB et al. 2016 [19] revealed that ethanolic extract of liberica coffee beans have a higher antioxidant capacity $(2212.817 \pm 204.156 \mathrm{TE} \mathrm{mmol} / \mathrm{g}$ dried plant $)$ compared to robusta and arabica coffee (1691.492 $\pm 153.326 \mathrm{TE} \mathrm{mmol} / \mathrm{g}$ dried plant and $1627.089 \pm 158.675 \mathrm{TE} \mathrm{mmol} / \mathrm{g}$ dried plant). Meanwhile, the previous study [7] showed that robusta SCG (one of the significant residues of raw coffee when the coffee powder is treated by hot water) has the highest value of DPPH inhibition $41.63 \pm 0.04 \%$ among arabica and liberica SCG. From the studies above, it can be concluded that although liberica coffee beans are less popular and the SCG of liberica coffee gave the lower result, the antioxidant activity of liberica coffee extracts can be opposed to arabica coffee and robusta coffee [32-33].

The Antioxidant Activity Index (AAI) of various extracts from three different liberica coffee regions using DPPH and CUPRAC methods were shown in Figures 1 and 2. Those values were compared to AAI ascorbic acid as standard. The highest value of AAI means the extract has the most increased antioxidant activity. A sample was stated to have a very strong antioxidant activity if the AAI value obtained above 2, strong antioxidant activity if the AAI value $1-2$, moderate antioxidant if the AAI value $0.5-1$, and weak antioxidant if the AAI value under 0.5 [34].

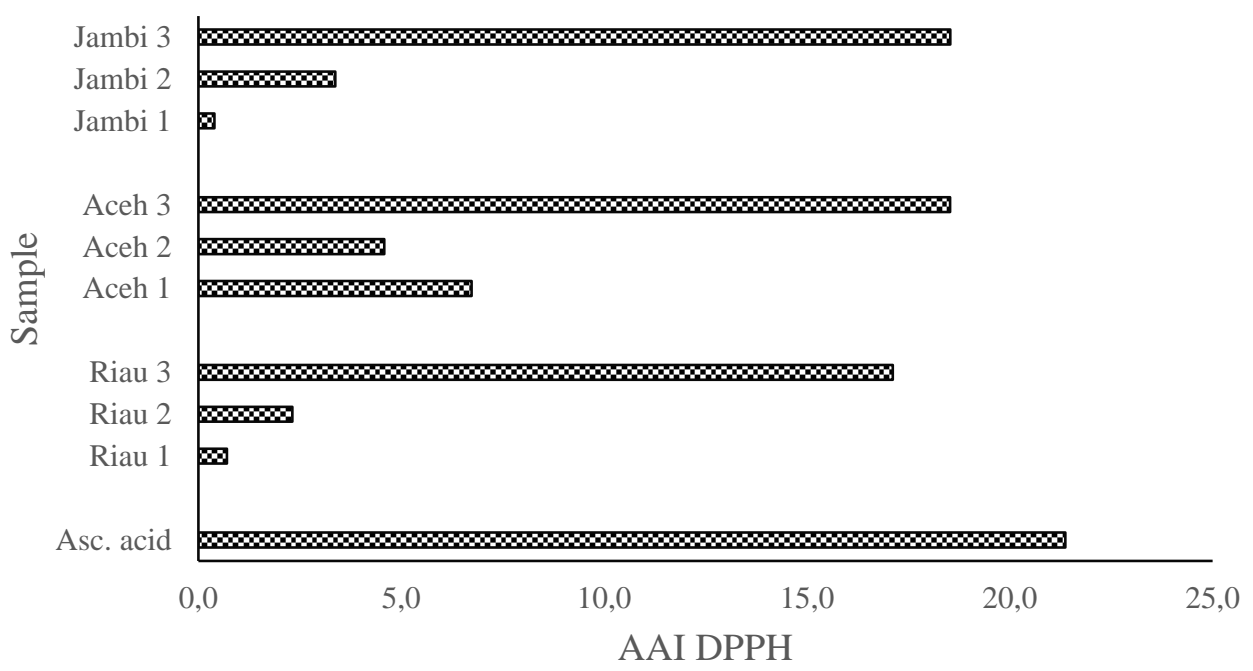

Figure 1. Antioxidant activity index data of liberica coffee beans by DPPH method.

The present study results showed that the highest AAI of DPPH and CUPRAC methods from $n$-hexane extracts were given by liberica coffee from Aceh (A1) $(6.74 \pm 0,26$ and $0.58 \pm$ 0.004). The highest AAI of DPPH and CUPRAC methods from ethyl acetate extracts were also given by liberica coffee from Aceh (A2) $(4.58 \pm 0.24$ and $2.33 \pm 0.015)$. In contrast, liberica coffee from Jambi was the highest AAI of DPPH and CUPRAC methods from ethanolic 
extracts $(\mathrm{J} 3)(18.54 \pm 1.49$ and $4.67 \pm 0.03)$. From all the data in Figure 1, it can be stated that AAI from the DPPH method of various extracts of liberica coffee medium roasted from three different regions ranged from 0.40 to 18.54 . The lowest index showed by $n$-hexane extract from Jambi (J1) (0.40 \pm 0.03$)$, and the highest index showed by an ethanolic extract from Jambi (J3) $(18.54 \pm 1.49)$. Meanwhile, AAI from the CUPRAC method of various extracts of liberica coffee medium roasted from three different regions in Figure 2 ranged from 0.53 to 4.67. The lowest index showed by n-hexane extract from Jambi (J1) $(0.53 \pm 0.002)$, while the ethanolic extract from Jambi showed the highest value (J3) (4.67 \pm 0.03$)$. The AAI of ascorbic acid from DPH and CUPRAC methods were $21.37 \pm 0.03$ and $21.99 \pm 1.87$.

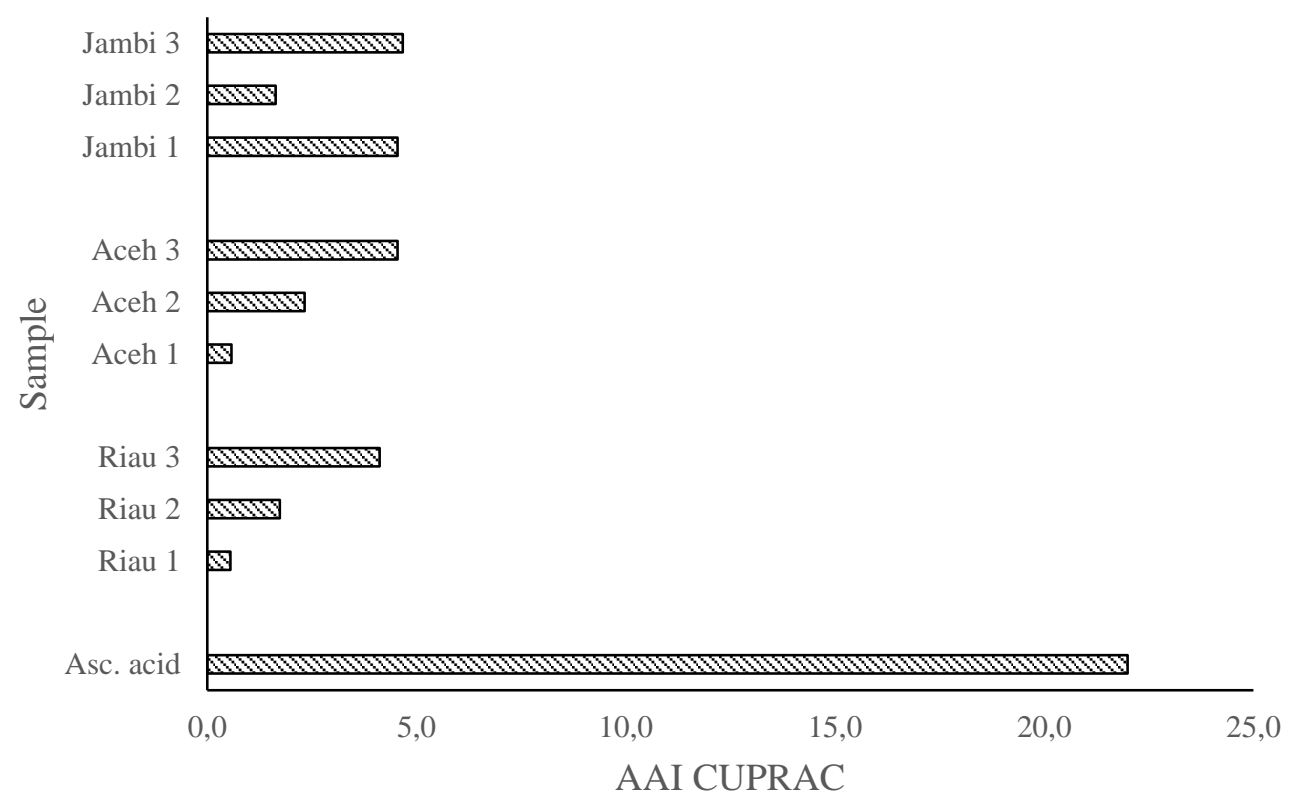

Figure 2. Antioxidant activity index data of liberica coffee by CUPRAC method.

A previous study [35] used the same solvents as the present study (n-hexane, ethyl acetate, and ethanol). However, the samples are arabica green coffee beans from three regions. $\mathrm{IC}_{50}$ of the DPPH method ranged from 0.70 to $134.56 \mathrm{mg} / \mathrm{mL}$. The highest value showed by ethanolic extract, and the n-hexane extract showed the lowest value. The result is the same as this study. Research by Acidri R et al. 2020 [17] showed the IC50 DPPH of roasted arabica coffee beans $(29.3 \pm 1.40 \mu \mathrm{g}$ sample/mL) was lower than the antioxidant activity of arabica green beans $(35.4 \pm 1.49 \mu \mathrm{g}$ sample $/ \mathrm{mL})$. The roasted arabica coffee beans have a higher antioxidant capacity than the unroasted arabica coffee beans. The increase reached $68.8 \%$ conventional one. This showed that the roasting process is essential in forming new Maillard reaction products that influence coffee's antioxidant activity [36]. Antioxidant activities determination by Pokorna J et al. 2015 [20] using the DPPH method revealed that methanolic extract of medium roasted Arabica coffee and the robusta coffee had a similar result $(113 \pm 20$ $\mu \mathrm{mol}$ Trolox/g of sample and $111 \pm 10 \mu \mathrm{mol}$ Trolox/g of the sample).

Meanwhile, the results for unroasted arabica coffee and the robusta coffee have quite different results $(83 \pm 18 \mu \mathrm{mol}$ Trolox/g of sample and $116 \pm 15 \mu \mathrm{mol}$ Trolox/g of the sample). Jeszka-Skowron M et al. 2016 [18] found that the robusta coffee extract has a more reducing compound than arabica coffee extract when the antioxidant activity is measured CUPRAC method. Green coffee beans from Vietnam showed the highest antioxidant activity $(7.49 \pm 0.04$ $\mathrm{mM}$ Trolox $/ \mathrm{kg}$ ). While the most increased antioxidant activity of arabica coffee was obtained from Brazil green coffee beans $(5.11 \pm 0.17 \mathrm{mM}$ Trolox $/ \mathrm{kg})$. 
Table 1. Total phenolic content of liberica coffee from three different regions.

\begin{tabular}{l|c|c|c}
\multirow{2}{*}{ Sample } & \multicolumn{3}{|c}{ Total Phenolic $(\mathbf{g}$ GAE/100 g) } \\
\cline { 2 - 4 } & n-Hexane Extract & Ethyl Acetate Extract & Ethanol Extract \\
\hline Riau & $1.03 \pm 0.05^{\mathrm{a}}$ & $2.77 \pm 0.09^{\mathrm{a}}$ & $17.85 \pm 0.50^{\mathrm{a}}$ \\
\hline Aceh & $0.81 \pm 0.05^{\mathrm{b}}$ & $7.70 \pm 0.16^{\mathrm{b}}$ & $22.59 \pm 1.61^{\mathrm{b}}$ \\
\hline Jambi & $0.78 \pm 0.38^{\mathrm{a}}$ & $3.38 \pm 0.13^{\mathrm{b}}$ & $21.26 \pm 0.63^{\mathrm{b}}$ \\
a-c = Different letters in one column indicate a significant difference $(\mathrm{p}<0.05)$
\end{tabular}

Total phenolic content (TPC) among various extracts determined using the gallic acid calibration curve equation as gallic acid equivalent (GAE). The calibration curve equation obtained is $\mathrm{y}=0.0056 \mathrm{x}+0.0223, \mathrm{R}^{2}=0.9983$. The TPC in various extracts from three different liberica coffee regions had a different result in the range $0.78-22.59 \mathrm{~g}$ GAE$/ 100 \mathrm{~g}$. The highest result was given by ethanolic extract of Aceh liberica coffee (A3) $(22.59 \pm 1.61 \mathrm{~g} \mathrm{GAE} / 100 \mathrm{~g})$. The lowest value was given by $\mathrm{n}$-hexane extracts of Jambi liberica coffee (J1) $(0.78 \pm 0.38 \mathrm{~g}$ GAE/100 g) (Table 1).

Similar results are also given by the previous study [35]. The TPC in various extracts from three different arabica coffee expressed results ranged from 0.75 to $70.55 \mathrm{~g} \mathrm{GAE} / 100 \mathrm{~g}$. Ethanolic extract of Mandailing arabica coffee showed the highest value (70.55 g GAE/100 g), and the lowest results were given by its n-hexane extract $(0.75 \mathrm{~g} \mathrm{GAE} / 100 \mathrm{~g})$. These studies showed that ethanolic extract had the highest TPC while the n-hexane extract presented the lowest value.

Saw AK et al. 2015 [21] stated that green beans of liberica coffee have the highest TPC, followed by robusta coffee and arabica coffee. However, AAI results using the DPPH method revealed that green beans of liberica coffee have the most increased antioxidant activity, followed by arabica coffee and robusta coffee. This slight difference is due to the lack of the TPC determination method itself, whichever the formed blue complexes. The electron transfer from the phenolic compounds in alkaline medium to molybdenum was not specific. It shows the results from phenolic compounds and the other reducing species like ascorbic acid, aromatic amines, and even sugars can give a positive response [37-40]. The previous study by Mubarak A et al. 2019 [23] expressed that TPC from unroasted liberica coffee beans experienced a significant increase in medium-dark liberica coffee beans. Acidri R et al. 2020 [17] also showed that arabica coffee, which passed the roasting process, gave higher TPC (35.4 $\pm 1.49 \mathrm{mg}$ g-1 GAE) than the green bean one $(29.3 \pm 1.40 \mathrm{mg} / \mathrm{g} \mathrm{GAE})$. However, research by Pokorna J et al., 2015 [20] exposed different results.

As a complete result, TPC from coffee beans decreased during the roasting process. Although the TPC from lightly roasted beans $9 \%$ higher than the green beans, the TPC then reduced $16 \%$ on the medium roasted beans and $30 \%$ on the dark roasted coffee beans. From all of the previous studies, it can be exposed that high temperatures and low water level conditions during the roasting process are related to the formation of new Maillard reaction products. The reaction that occurs involved phenolic compounds, which became part of melanoidins [41]. The enhanced result can appear because the increased of formed melanoidins react with the Folin Ciocalteu's reagent [42]. But, during the severe roasting process, the phenolic compound may be degraded [43].

Total flavonoid content (TFC) in various extracts were expressed in quercetin equivalent using the quercetin curve equation $\mathrm{y}=0.0042 \mathrm{x}+0.0739, \mathrm{R}^{2}=0.9911$. The TFC in various extracts from three different regions of liberica coffee had a different result in the range $2.55-4.93 \mathrm{~g} \mathrm{QE} / 100 \mathrm{~g}$. The highest flavonoid content $(4.93 \pm 0.36 \mathrm{~g} \mathrm{QE} / 100 \mathrm{~g})$ for ethanol 
extract of Aceh liberica coffee (A3), while the lowest flavonoid content $(2.55 \pm 0.21 \mathrm{~g} \mathrm{QE} / 100$ g) were given by the ethyl acetate extract of Riau liberica coffee (R2) (Table 2).

Table 2. Total flavonoid content of liberica coffee from three different regions.

\begin{tabular}{l|c|c|c}
\multirow{2}{*}{ Sample } & \multicolumn{3}{|c}{ Total Flavonoid $(\mathbf{g}$ QE/100 g) } \\
\cline { 2 - 4 } & n-Hexane Extract & Ethyl Acetate Extract & Ethanol Extract \\
\hline Riau & $4.31 \pm 0.05^{\mathrm{a}}$ & $2.55 \pm 0.21^{\mathrm{a}}$ & $3.78 \pm 0.12^{\mathrm{a}}$ \\
\hline Aceh & $4.56 \pm 0.44^{\mathrm{a}}$ & $4.93 \pm 0.36^{\mathrm{b}}$ & $3.36 \pm 0.09^{\mathrm{b}}$ \\
\hline Jambi & $2.58 \pm 0.25^{\mathrm{b}}$ & $4.71 \pm 0.39^{\mathrm{b}}$ & $4.33 \pm 0.14^{\mathrm{c}}$ \\
a-c = Different letters in one column indicate a significant difference $(\mathrm{p}<0.05)$
\end{tabular}

The previous study [35] stated that TFC from various extracts of arabica coffee beans from three different regions were in the range of 3.04-7.41 g QE/100 g. Compared with the present study, these arabica green coffee beans have a higher TFC than medium roasted liberica coffee beans. Research by Abdeltaif SA et al. 2018 [44] also exposed that raw coffee beans have a higher TFC (52.07 mg catechin/g) than roasted coffee beans (30.65 mg catechin/g).

The correlation between phenolic and flavonoid content in the various extracts of liberica coffee from Riau, Aceh, and Jambi against AAI DPPH and AAI CUPRAC statistically tested using Pearson's method. The TPC and TFC are stated to contribute to antioxidant activity if they positively and positively correlate to AAI DPPH and AAI CUPRAC. This indicated that the higher TPC and TFC display the higher antioxidant activity of the sample.

The data in Table 3 exposed that the phenolic content in various extracts of liberica coffee from Riau, Aceh, and Jambi gave positive and high correlation with the DPPH AAI ( $\mathrm{r}$ $=0.998, \mathrm{p}<0.01 ; \mathrm{r}=0.885, \mathrm{p}<0,01 ; \mathrm{r}=0.993, \mathrm{p}<0.01)$. Other than that, this study exhibited positive and high correlation between TPC of various extracts of liberica coffee from Riau, Aceh, and Jambi with the CUPRAC AAI $(r=0.972, \mathrm{p}<0.01 ; \mathrm{r}=0.988, \mathrm{p}<0.01 ; \mathrm{r}=0.989$, $\mathrm{p}<0.01)$. There was no flavonoid content of liberica coffee extracts that positively correlated with AAI DPPH and AAI CUPRAC.

Table 3. Pearson's correlation coefficient of total phenol and flavonoid of liberica coffee from three different regions with AAI DPPH and AAI CUPRAC.

\begin{tabular}{l|c|c}
\multirow{2}{*}{ Antioxidant parameter } & \multicolumn{2}{|c}{ Pearson's correlation coefficient (r) } \\
\cline { 2 - 3 } & Total phenol & Total flavonoid \\
\hline AAI DPPH Riau & $0.998^{* *}$ & $0.133^{\mathrm{ns}}$ \\
\hline AAI DPPH Aceh & $0.885^{* *}$ & $-0.915^{* *}$ \\
\hline AAI DPPH Jambi & $0.993^{* *}$ & $0.473^{\mathrm{ns}}$ \\
\hline AAI CUPRAC Riau & $0.972^{* *}$ & $-0.103^{\mathrm{ns}}$ \\
\hline AAI CUPRAC Aceh & $0.988^{* *}$ & $-0.720^{*}$ \\
\hline AAI CUPRAC Jambi & $0.989^{* *}$ & $0.561^{\mathrm{ns}}$ \\
ns = not significant, & $*$ significant at $\mathrm{p}<0.05,{ }^{* *}=$ significant at $\mathrm{p}<0.01$
\end{tabular}

The structure of these compounds can influence the antioxidant activity provided by phenol group compounds. The more hydroxyl groups in the aromatic ring and the orthodiphenol structure will strengthen the antioxidant activity [45].

Other than that, the flavonoid compound's antioxidant activity can also be affected by the structure of these compounds [46]. Flavonoids with ortho at- $\mathrm{OH}$ groups in $\mathrm{C}-3$ '-C-4', OH groups in $\mathrm{C}-3$, ketone groups in $\mathrm{C}-4$, double bonds in $\mathrm{C}-2$, and $\mathrm{C}-3$ will provide high antioxidant activity. However, glycosylated flavonoid compounds will reduce their antioxidant activity because the number of hydroxy groups will also decrease [47].

The correlation between DPPH and CUPRAC AAI in the various liberica coffee extracts from Riau, Aceh, and Jambi were statistically tested using the Pearson method. The data in Table 4 revealed that there were positive and high correlation between AAI DPPH and 
AAI CUPRAC in liberica coffee extracts from Riau, Aceh, and Jambi ( $\mathrm{r}=0.970, \mathrm{p}<0.01 ; \mathrm{r}=$ $0.822, \mathrm{p}<0.01 ; \mathrm{r}=0.99, \mathrm{p}<0.01)$. This result indicated the existence of linear results between the two methods.

Table 4. Pearson's correlation coefficient between DPPH and CUPRAC methods.

\begin{tabular}{l|c|c|c}
\multirow{2}{*}{ Antioxidant parameter } & \multicolumn{3}{|c}{ Pearson's correlation coefficient (r) } \\
\cline { 2 - 4 } & $\begin{array}{c}\text { AAI CUPRAC } \\
\text { Riau }\end{array}$ & $\begin{array}{c}\text { AAI CUPRAC } \\
\text { Aceh }\end{array}$ & $\begin{array}{c}\text { AAI CUPRAC } \\
\text { Jambi }\end{array}$ \\
\hline AAI DPPH Riau & $0.970^{* *}$ & & \\
\hline AAI DPPH Aceh & & $0.822^{* *}$ & $0.990^{* *}$ \\
\hline $\begin{array}{l}\text { AAI DPPH Jambi } \\
\text { A* significant at } \mathrm{p}<0.01\end{array}$ & &
\end{tabular}

\section{Conclusions}

The determination of the antioxidant activity of liberica coffee from Riau, Aceh, and Jambi demonstrated AAI DPPH in the range of 0.397- 18.536, while CUPRAC 0.532-4.674. The highest TPC in ethanol extract of liberica coffee from Aceh $(22.585 \pm 1.610 \mathrm{~g} \mathrm{GAE} / 100$ $\mathrm{g})$ and the highest TFC in ethyl acetate extract of liberica coffee from Aceh $(4.927 \pm 0.355 \mathrm{~g}$ QE/100 g). TPC of all samples had a positive and significant correlation with AAI DPPH and CUPRAC. AAI DPPH and CUPRAC values gave a significant and positive correlation. Ethyl acetate and ethanol extracts of liberica coffee from three different regions were strong to very strong antioxidants. TPC of liberica coffee from three other areas contributed to antioxidant activity by DPPH dan CUPRAC methods. The two methods showed linear results in the antioxidant activities of liberica coffee from three regions.

\section{Funding}

This work was funded by Research, Community Service and Innovation Program for Research Group from the Institute for Research and Community Service - Bandung Institute of Technology, grant number A14/SK/I1.CO3/KP/2020.

\section{Acknowledgments}

The authors wish to respect the facilities support of the Department of Pharmaceutical Biology, School of Pharmacy, Bandung Institute of Technology, Indonesia.

\section{Conflicts of Interest}

The authors declare no conflict of interest.

\section{References}

1. Lobo, V.; Patil, A.; Phatak, A.; Chandra, N. Free radicals, antioxidants, and functional foods: impact on human health. Pharmacogn Rev 2010, 4, 118-126, http://dx.doi.org/10.4103/0973-7847.70902.

2. Yashin, A.; Yashin Y.; Wang, J.Y.; Nemzer, B. Antioxidant and antiradical activity of coffee. Antioxidants 2013, 2, 230-245, https://doi.org/10.3390/antiox2040230.

3. Cordoba, N.; Pataquiva, L.; Osorio, C.; Moreno, F.L.M.; Ruiz, R.Y. Effect of grinding, extraction time and type of coffee on the physicochemical and flavour characteristics of cold brew coffee. Sci Rep. 2019, 8440, 1-12, https://doi.org/10.1038/s41598-019-44886-w.

4. Coso, J.D.; Salinero, J.J.; Lara, B.Effects of Caffeine and Coffee on Human Functioning. Nutrients 2020, 12, 1-5, https://doi.org/10.3390/nu12010125.

5. Thomas, D.R.; Hodges, I.D. Dietary Research on Coffee: Improving Adjustment for Confounding. Curr Dev Nutr 2020, 4, 1-44, https://doi.org/10.1093/cdn/nzz142. 
6. Janda, K.; Jakubczyk, K.; Baranowska-Bosiacka, I.; Kapczuk, P.; Kochman, J.; Rębacz-Maron, E.; Gutowska, I. Mineral Composition and Antioxidant Potential of Coffee Beverages Depending on the Brewing Method. Foods 2020, 9, 1-16, https://doi.org/10.3390/foods9020121.

7. Zainol, M.K.; Mohd Subri, I.; Zamri, A.I.; Mohd Zin, Z.; Fisal, A.; Mamat, H. Antioxidative properties and proximate analysis of spent coffee ground (SCG) extracted using ultrasonic-methanol assisted technique as a potential functional food ingredient. Food Res 2020, 4, 636-644, https://doi.org/10.26656/fr.2017.4(3).358.

8. Haile, M.; Bae, H.M.; Kang.W.H. Comparison of the antioxidant activities and volatile compounds of coffee beans obtained using digestive bio-processing (elephant dung coffee) and commonly known processing methods. Antioxidants 2020, 9, 1-21, https://doi.org/10.3390/antiox9050408.

9. Ormaza-Zapata, A.M.; Díaz-Arango, F.O.; Rojano, B.A. The effect of pressure filtration coffee preparation methods (Coffea arabica 1. var. castillo) on antioxidant content and activity, and beverage acceptance. DYNA 2019, 86, 261-270, http://doi.org/10.15446/dyna.v86n209.75839.

10. Bolka, M.; Emire, S. Effects of coffee roasting technologies on cup quality and bioactive compounds of specialty coffee beans. Food Sci Nutr 2020, 8, 1-11, https://doi.org/10.1002/fsn3.1904.

11. Bauer, D.; Abreu, J.; Jordao, N.; Rosa, J.S.; Freitas-Silva, O; Teodoro, A. Effect of roasting levels and drying process of Coffea canephora on quality of bioactive compounds and cytotoxicity. Int J Mol Sci 2018, 19, 119, https://doi.org/10.3390/ijms19113407.

12. Montavon, P.; Mauron, A.; Duruz E. Changes in green coffee protein profiles during roasting. J Agric Food Chem 2003, 51, 2335-2343, https://doi.org/10.1021/jf020832b.

13. Blois, M.S. Antioxidant determination by the use of stable free radicals. Nature Struct Biol 1958, 181, 11992000, https://doi.org/10.1038/1811199a0.

14. Apak, R.; Shela, G.; Volker, B.; Karen, M.S.; Mustafa, Ö.; Kubilay, G. Methods of measurement and evaluation of natural antioxidant capacity/activity. Pure Appl Chem 2013, 85, 957-998, https://doi.org/10.1351/PAC-REP-12-07-15.

15. Pourmorad, F.; Hosseinimehr, S.; Shahabimajd, N. Antioxidant activity, phenol and flavonoid contents of some selected Iranian medicinal plants. Afr J Biotechnol 2006, 5, 1142-1145.

16. Chang, C.C.; Yang, M.H.; Wen, H.M.; Chern, J.C. Estimation of total flavonoid content in propolis by two complementary colorimetric methods. J Food Drug Anal 2002, 10, 178-182, https://doi.org/10.38212/22246614.2748.

17. Acidri, R.; Sawai, Y.; Sugimoto, Y.; Handa, T.; Sasagawa, D.; Masunaga, T.; Yamamoto, S.; Nishihara, E. Phytochemical profile and antioxidant capacity of coffee plant organs compared to green and roasted coffee beans. Antioxidants 2020, 9, 1-17, https://doi.org/10.3390/antiox9020093.

18. Jeszka-Skowron, M.; Sentkowska, A.; Pyrzynska, K.; Pena, M.P.D. Chlorogenic acids, caffeine content and antioxidant properties of green coffee extracts: influence of green coffee bean preparation. Eur Food Res Technol 2016, 242, 1403-1409, https://doi.org/10.1007/s00217-016-2643-y.

19. Patay, E.B.; Sali, N.; Koszegi, T.; Csepregi, R.; Balazs, V.L.; Nemeth, T.S. Antioxidant potential, tannin and polyphenol contents of seed and pericarp of three Coffea species. Asian Pac J Trop Med 2016, 9, 366-371, https://doi.org/10.1016/j.apjtm.2016.03.014.

20. Pokorna, J.; Venskutonis, P.R.; Kraujalyte, V.; Kraujalis, P.K.; Dvorak, P.; Tremlova, B.; Kopriva, V.; Ostadalova, M. Comparison of different methods of antioxidant activity evaluation of green and roast $C$. arabica and C. robusta coffee beans. Acta Aliment Hung 2015, 44 454-460, https://doi.org/10.1556/066.2015.44.0017.

21. Saw, A.K.; Yam, W.; Wong, K.; Lai, C. A comparative study of the volatile constituents of southeast Asian Coffea arabica, Coffea liberica and Coffea robusta green beans and their antioxidant activities. J Essent Oil Bear Pl 2015, 18, 64-73, https://doi.org/10.1080/0972060X.2014.977580.

22. Fuster, M.D.; Mitchell, A.E.; Ochi, H.; Shibamoto, T. Antioxidative activities of heterocyclic compounds formed in brewed coffee. J Agric Food Chem 2000, 48, 5600-5603, https://doi.org/10.1021/jf000605e.

23. Mubarak, A.; Croft, K.D.; Bondonno, C.B.; Din, N.S. Comparison of liberica and arabica coffee: chlorogenic acid, caffeine, total phenolic and DPPH radical scavenging activity. Asian J Agric Biol 2019, 7, 130-136.

24. Sacchetti, G.; Mattia, C.; Pittia, P.; Mastrocola, D. Effect of roasting degree, equivalent thermal effect and coffee type on the radical scavenging activity of coffee brews and their phenolic fraction. J Food Eng 2009, 90, 74-80, https://doi.org/10.1016/j.jfoodeng.2008.06.005.

25. Górecki, M.; Hakkmann, E. The antioxidant content of coffee and its in vitro activity as an effect of its production method and roasting and brewing time. Antioxidants 2020, 9, 1-10, https://doi.org/10.3390/antiox9040308.

26. Laukaleja, I.; Kruma, Z. Influence of the roasting process on bioactive compounds and aroma profile in specialty coffee. FoodBalt 2019, 246, 7-12, https://doi.org/10.1007/s00217-019-03388-9.

27. Masek, A.; Latos-Brozio, M.; Kałuzna-Czaplinska, J.; Rosiak, A.; Chrzescijanska, E. Antioxidant Properties of Green Coffee Extract. Forests 2020, 11, 1-13, https://doi.org/10.3390/f11050557.

28. Mehaya, F.M.; Mohammad, A.A. Thermostability of bioactive compounds during roasting process of coffee beans. Heliyon 2020, 6, 1-7, https://doi.org/10.1016/j.heliyon.2020.e05508.

29. Ozuna, C.; Mulík, S.; Valdez-Rodríguez, B.; Abraham-Juárez, M.R.; Fernández-López, C.L. The effect of organic farming on total phenols, total flavonoids, brown compounds and antioxidant activity of spent coffee 


grounds from Mexico. Biol Agric Hortic $\mathbf{2 0 2 0} \quad$ 36,
https://doi.org/10.1080/01448765.2019.1704876.

30. Liang, N.; Kitts, D.D. Antioxidant property of coffee components: assessment of methods that define mechanism of action. Molecules 2014, 19, 19180-19208, https://doi.org/10.3390/molecules191119180.

31. Yanagimoto, K.; Lee, K.G.; Ochi, H.; Shibamoto, T. Antioxidative activity of heterocyclic compounds found in coffee volatiles produced by Maillard reaction. J Agric Food Chem 2002, 50, 5480-5484, https://doi.org/10.1021/jf025616h.

32. Lim, T.K. Coffea liberica inedible medicinal and non-medicinal plants. Dordrecht Springer 2013, 710-714.

33. Teo, H.M.; Yam, W.S.; Lai, C.S. Antioxidative activities of Coffea liberica green beans and its phytochemical constituents. Pharmacil Pharm Sci 2014, 1.

34. Scherer, R.; Godoy, H. Antioxidant activity index by the 2,2-diphenyl-1-picrylhydrazyl method. Food Chem 2009, 112, 654-658, https://doi.org/10.1016/j.foodchem.2008.06.026.

35. Fidrianny, I.; Annisa, Ruslan, K. Antioxidant activities of arabica green coffee from three regions using ABTS and DPPH assays. Asian J Pharm Clin Res 2016, 9, 189-193.

36. O'Keefe, J.H.; Bhatti, S.K.; Patil, H.R.; Dinicolantonio, J.J.; Lucan, S.C.; Lavie, C.J. Effects of habitual coffee consumption on cardiometabolic isease, cardiovascular health, and all-cause mortality. J Am Coll Cardiol 2013, 62, 1043-1051, https://doi.org/10.1016/j.jacc.2013.06.035.

37. Ainsworth, E.A.; Gillespie, K.M. Estimation of total phenolic content and other oxidation substrates in plant tissues using Folin-Ciocalteu reagent. Nat Protoc 2007, 2, 875-877, https://doi.org/10.1038/nprot.2007.102.

38. Huang, D.; Ou, B.; Prior, R.L. The chemistry behind antioxidant capacity assays. J Agric Food Chem 2005, 53, 1841-1856, https://doi.org/10.1021/jf030723c.

39. Karadag, A.; Ozcelik, B.; Saner, S. Review of methods to determine antioxidant capacities. Food Anal Methods 2009, 2, 41-60.

40. Bobková, A.; Hudáček, M.; Jakabová, S.; Belej, L.; Capcarová, M.; Čurlej, J.; Bobko, M.; Árvay, J.; Jakab, I.; Čapla, J.; Demianová, A. The effect of roasting on the total polyphenols and antioxidant activity of coffee. J Environ Sci Health B 2020, 55, 495-500, https://doi.org/10.1080/03601234.2020.1724660.

41. Bakedam, E.K.; Schols, H.A.; Boekel, M.A.J.S.; Smith, G. Incorporation of chlorogenic acids in coffee brew melanoidins. J Agr Food Chem 2008, 56, 2055-2063, https://doi.org/10.1021/jf073157k.

42. Lopez-Galilea, I.; Paz de Pena, M.; Cid, C. Correlation of selected constituents with the total antioxidant capacity of coffee beverages: influence og the brewing procedure. J Agric Food Chem 2007, 55, 6110-6117, https://doi.org/10.1021/jf070779x.

43. Trugo, L.C.; Macrae, R. A study of the effect of roasting on the chlorogenic acid composition of coffee using HPLC. Food Chem 1984, 15, 219-227, https://doi.org/10.1016/0308-8146(84)90006-2.

44. Abdeltaif, S.A.; SirElkhatim, K.A.; Hassan, A.B. Estimation of phenolic and flavonoid compounds and antioxidant activity of spent coffee and black tea (processing) waste for potential recovery and reuse in Sudan. Recycl 2018, 3, 1-9, https://doi.org/10.3390/recycling3020027.

45. Aberoumand, A.; Deokule, S.S. Comparison of phenolic compounds of some edible plants of Iran and India, Pak J Nutr 2008, 7, 582-585, https://doi.org/10.3923/pjn.2008.582.585.

46. Kopustinskiene, D.K.; Jakstas, V.; Savickas, A, Bernatoniene, J. Flavonoids as Anticancer Agents. Nutrients 2020, 12, 1-25, https://doi.org/10.3390/nu12020457.

47. Shahidi, F.; Janitha, P.K.; Wanasundara, P.D. Phenolic antioxidants. Critical Reviews in Food Science and Nutrition 1992, 32, 67-103, https://doi.org/10.1080/10408399209527581. 